\title{
BIOCOMPATIBILITY OF HEPARIN-COATED EXTRACORPOREAL BYPASS CIRCUITS: A RANDOMIZED, MASKED CLINICAL TRIAL
}

Derek D. Muehrcke, $\mathrm{MD}^{\mathrm{a}}$ Patrick M. McCarthy, MD ${ }^{a}$ Kandice Kottke-Marchant, MD $^{\mathrm{b}}$ Hiroaki Harasaki, $\mathrm{MD}, \mathrm{PhD}^{\mathrm{c}}$

Jean Pierre-Yared, $\mathrm{MD}^{\mathrm{d}}$ Judith A. Borsh, RN ${ }^{\mathrm{a}}$

David A. Ogella, CCP

Delos M. Cosgrove, MD $^{a}$
Cardiopulmonary bypass circuits cause morbidity during cardiac operations. Plasma proteins and cellular components are stimulated by contact with the cardiopulmonary bypass circuit and can cause bleeding and postperfusion syndrome. This is especially true in patients undergoing reoperative cardiac procedures, which carries a higher risk of postoperative bleeding and prolonged ventilation compared with primary cardiac surgical procedures. Recently, cardiopulmonary bypass circuit surfaces have been coated with antithrombotic agents to improve their biocompatibility. This study evaluated the effect of a heparin-coated cardiopulmonary bypass system (Duraflo II, Baxter Bentley Healthcare Systems, Irvine, Calif.) on thrombin formation, platelet stimulation, and leukocyte activation in patients undergoing reoperative coronary artery bypass grafting or valve operation. Fifty patients were selected and randomly assigned to a standard noncoated control system ( $n=26)$ or the Duraflo heparin-coated system $(n=24)$. Similar heparin doses were used in both groups $(3 \mathrm{mg} / \mathrm{kg})$. The heparin-coated group used a completely heparin-coated bypass circuit including the cardiotomy reservoir; arterial filters were heparin-coated in both groups. Samples were obtained before cardiopulmonary bypass, 30 minutes into cardiopulmonary bypass, 5 minutes after crossclamp removal, and 5 minutes after protamine administration. Thrombin formation (thrombin-antithrombin III by enzyme-linked immunosorbent assays) and platelet activation ( $\beta$-thromboglobulin by enzyme-linked immunosorbent assays; P-selectin expression by flow cytometry) were assayed. Leukocyte activation was determined by quantitative and qualitative analysis of arterial filters by scanning electron microscopy in six patients from each group. In both circuits, thrombin values increased markedly 30 minutes into cardiopulmonary bypass compared with baseline values $(p<0.001)$ (heparin-coated, $7 \pm 5$ to $96 \pm 115 \mathrm{ng} / \mathrm{ml}$; noncoated, $10 \pm 9$ to $115 \pm 125$ $\mathrm{ng} / \mathrm{ml}$ ). Platelet activation as measured by $\beta$-thromboglobulin (heparincoated, $104 \pm 100$ to $284 \pm 166 \mathrm{IU} / \mathrm{ml}$; noncoated, $81 \pm 74$ to $288 \pm 277$ $\mathrm{IU} / \mathrm{ml}$ ) and P-selectin expression (heparin-coated, $1.5 \% \pm 1.5 \%$ to $6.4 \% \pm$ $6.1 \%$; noncoated, $1.4 \% \pm 1.1 \%$ to $6.2 \% \pm 4.3 \%$ ) also significantly increased 30 minutes into cardiopulmonary bypass compared with baseline values $(p<0.001)$. Platelet activation and thrombin generation did not differ between the two circuits at any time. Granulocyte activation and platelet deposition did not differ between the two circuits when arterial filters were evaluated. Both groups had similar heparin and protamine administration, blood transfusions, postoperative alveolar-arterial oxygen gradient, time to
From the Departments of Thoracic and Cardiovascular Surgery, ${ }^{\mathrm{a}}$ Clinical Pathology, ${ }^{\mathrm{b}}$ Biomedical Engineering, ${ }^{\mathrm{c}}$ Cardiothoracic Anesthesia, ${ }^{\mathrm{d}}$ and Perfusion Services, ${ }^{\mathrm{e}}$ The Cleveland Clinic Foundation, Cleveland, Ohio.

Supported by a grant from The Baxter Corporation.

Received for publication August 4, 1995; revisions requested Sept. 11, 1995; revisions received Oct. 3, 1995; accepted for publication Oct. 20, 1995.
Address for reprints: Derek D. Muehrcke, MD, Department of Thoracic and Cardiovascular Surgery, F-25, The Cleveland Clinic Foundation, 9500 Euclid Ave., Cleveland, OH 44195.

J Thorac Cardiovasc Surg 1996;112:472-83

Copyright (c) 1996 by Mosby-Year Book, Inc.

$0022-5223 / 96 \$ 5.00+0 \quad \mathbf{1 2 / 1 / 7 0 1 3 5}$ 
extubation, length of intensive care unit stay, and overall morbidity and mortality. Clinical outcome and blood loss did not differ between the groups. We conclude that heparin-coated cardiopulmonary bypass circuits did not improve biochemical or clinical markers of biocompatibility in a reoperative patient population. (J Thorac Cardiovasc Surg 1996;112:472-83)

C rdiopulmonary bypass $(\mathrm{CPB})$ is associated with a diffuse systemic inflammatory response that can cause considerable morbidity, including organ dysfunction and bleeding. ${ }^{1-5}$ The interaction of blood components with the artificial surfaces of the bypass circuit induces contact activation of the humoral amplification system, including the complement, kallikrein, coagulation, and fibrinolytic cascades, along with deposition and activation of leukocytes and platelets. Considerable efforts have been made to reduce the damaging effect of CPB by modifying the materials used in the extracorporeal bypass circuit. Altering the blood-contacting surfaces of the extracorporeal circuit may make these surfaces more biocompatible, thus reducing organ dysfunction and perioperative morbidity.

Early experimental and clinical studies of heparin-coated surfaces during primary cardiac operations have revealed less blood cell trauma, reduced leukocyte activation, less perioperative blood loss, and decreased activation of the complement cascades, all of which suggests improved biocompatibility. ${ }^{6-9}$ However, most clinical studies have excluded patients undergoing the high-risk procedures of reoperation, valve replacement, or combined coronary artery bypass grafting and valve replacement operation. ${ }^{10}$ Further, in other studies, ${ }^{11,12}$ the cardiotomy reservoir was not heparin-coated, introducing a possible compounding factor. The present study investigated the biocompatibility of heparincoated extracorporeal bypass circuits in a patient population undergoing reoperative coronary artery bypass grafting, valve replacement, or both as practiced at a referral center for cardiovascular and thoracic surgery. Presumably, any clinically significant improvement resulting from improved biocompatibility of heparin-coated systems might be heightened in this population. Our study is also unique in that a heparin-coated cardiotomy reservoir was included in our treatment group such that all bloodcontacting surfaces were heparin coated. Thus any biomaterial-dependent activation of the body's inflammatory response could not be attributed to the uncoated cardiotomy reservoir.

\section{Patients and methods}

This study involved 50 patients undergoing elective cardiac reoperation for coronary artery bypass grafting, valve operation, or both coronary artery bypass grafting and valve operation. Patients were selected and randomly assigned to the control group $(n=26)$ or the treatment group $(n=24)$. In the treatment group, all bloodcontacting surfaces of the bypass circuit were heparin coated, except for the infusion catheters for the cardioplegic solution. In the control group, an identical bypass circuit, including oxygenator and cannulas, was used but was not heparin-coated. The surgeons and study nurse were blinded as to the group assignments of the patients. Informed consent was obtained by a protocol approved by the Cleveland Clinic Foundation institutional review board. Inclusion criteria included all patients undergoing elective reoperative coronary artery bypass or valve operation. Exclusion criteria consisted of the following: (1) emergency operation, (2) known coagulopathy, (3) endocarditis, (4) preoperative intra-aortic balloon pump, and (5) inability to obtain informed consent. For randomization, the perfusionist drew sealed envelopes just before setting up the operation.

Bypass circuits. Identical cardiopulmonary system configurations were used for both groups. However, in the treatment group, the circuit, the cardiotomy reservoir, and cannulas were heparin-coated with Duraflo II (Bentley Baxter Healthcare Systems, Irvine, Calif.). In both systems, the arterial filter was heparin coated. ${ }^{8}$ The bypass system consisted of a roller-head pump, Bentley AF-1025 arterial filter, Bentley-HSR 4000 venous reservoir and cardiotomy autotransfusion filter, Bentley Univox membrane oxygenator, Bentley. HE-30 cardioplegic heat-exchange system, Bentley BCR-3500 cardiotomy reservoir, RMI (Salt Lake City, Utah) aortic cannula (24F) and venous two-stage $(36 \mathrm{~F} / 52 \mathrm{~F})$ cannula, and Bentley custom tubing packs. The CPB circuits were primed with $1500 \mathrm{ml}$ of Plasma-Lyte solution (Baxter Healthcare, Deerfield, III.) and 5000 units of bovine heparin.

All patients were premedicated with scopolamine 0.2 to $0.4 \mathrm{mg}$ and morphine $0.1 \mathrm{mg} / \mathrm{kg}$ intramuscularly 1 hour before induction of anesthesia. Anesthesia was induced and maintained with a combination of fentanyl and midazolam supplemented with isoflurane. Neuromuscular blockade was obtained with pancuronium or vecuronium titrated to effect. The total doses of fentanyl and midazolam ranged from 40 to $50 \mathrm{mg} / \mathrm{kg}$ and 60 to $80 \mathrm{mg} / \mathrm{kg}$, respectively. All patients received $300 \mathrm{IU} / \mathrm{kg}$ of bovine heparin before aortic cannulation. Activated clotting time was measured with a Hemochron 801 instrument (International Technidyne, Edison, N.J.) and maintained at more than 480 seconds during the procedure with supplemental heparin. 
During CPB, patients were cooled so the rectal temperature was maintained at $28^{\circ} \mathrm{C}$ to $32^{\circ} \mathrm{C}$. After aortic crossclamping, cold blood $\left(4^{\circ} \mathrm{C}\right)$ or crystalloid cardioplegic solution was used to institute rapid diastolic arrest of the heart.

Our surgical strategy included the performance of distal bypass anastomoses initially whenever bypass grafting was part of the planned procedure. Saphenous vein anastomoses were done first then internal thoracic artery anastomoses (usually to the left anterior descending coronary artery). Associated valve procedures were done after all distal coronary artery anastomoses. Proximal vein graft anastomosis was done while the aorta was crossclamped.

While the patient was fully heparinized and supported by bypass, a cardiotomy suction device was used to return the shed pericardial blood to the systemic circulation. A cell-saving device (not heparin-coated) was used at all other times. Blood aspirated via the cell saving system was washed and not transferred until the patient had returned to the intensive care unit (ICU). Hematocrit value was maintained at $18 \%$ to $20 \%$ during bypass with blood transfusions. CPB was discontinued after the heart was deaired, provided that the bladder temperature was at least $36.5^{\circ} \mathrm{C}$ and cardiac function was good. Heparin effects were reversed by protamine sulfate administration after decannulation.

Blood lost postoperatively was collected with indwelling mediastinal and pleural chest tubes and was autotransfused for the first 8 postoperative hours. After operation, packed red blood cells were transfused to maintain a hematocrit level of at least $25 \%$. Platelet transfusions were given to patients with excessive bleeding. Fresh frozen plasma was administered to patients with both excessive bleeding and a prolonged prothrombin time. During this study no aprotinin was used; however, $\epsilon$-aminocaproic acid was used selectively before operation.

Data collection. All data were collected by one dedicated study nurse. Preoperative patient characteristics, including diagnosis, preoperative aspirin or heparin use, age, sex, and cardiac function, were recorded. All cases were assessed with the Higgins Severity Score to determine preoperative surgical risk. ${ }^{13}$ Intraoperative variables recorded included the number and type of bypass grafts done, valve procedures done, aortic crossclamp duration, CPB duration, blood volume administered, total heparin use, total protamine use, and need for $\epsilon$-aminocaproic acid. After operation, the amount of chest tube drainage and transfusion requirements were documented. Alveolar-arterial oxygen gradients 4 hours after admission to the ICU, length of assisted ventilation, and ICU length of stay were also recorded. Alveolar-arterial oxygen difference $\left(\mathrm{A}-\mathrm{aDO}_{2}\right.$ ) was calculated by the following equation:

$$
\mathrm{A}-\mathrm{aDO}_{2}=\mathrm{FiO}_{2}\left(\mathrm{P}_{\mathrm{stm}}-47\right)-\left(\mathrm{PaCO}_{2} \times 1.25\right)-\mathrm{PaO}_{2}
$$

where $\mathrm{FiO}_{2}$ is the inspired fraction of oxygen, $\mathrm{PaCO}_{2}$ is the arterial carbon dioxide tension, and $\mathrm{PaO}_{2}$ is the arterial oxygen tension. Because initial alveolar-arterial gradient after ICU admission typically is large, reflecting the effects of atelectasis, alveolar-arterial gradients were determined at 4 hours after operation. Furthermore, to standardize alveolar-arterial oxygen gradients to inspired fraction of oxygen during ventilation, respiratory indices (RI) were determined for each patient by the following equation:

$$
\mathrm{RI}=\frac{\mathrm{A}-\mathrm{aDO}_{2}}{\mathrm{PaO}_{2}}
$$

Patients were followed up during the entire hospital stay for the development of complications such as perioperative myocardial infarction (creatinine phosphokinase $\mathrm{MB}$ fraction greater than 100 units with either electrocardiographic changes or hemodynamic instability), adult respiratory distress syndrome, stroke, infection, need for reintubation because of respiratory distress, or death.

Measurements of biocompatibility indices. Plasma concentrations of platelet $\alpha$-granule product $\beta$-thromboglobulin $(\beta$-TG) and expression of the platelet surface marker P-selectin (CD 62) were measured to quantify platelet activation. Thrombin generation and inactivation by antithrombin III were measured by plasma determination of levels of thrombin-antithrombin III (TAT III) to quantify the degree of stimulation to the coagulation system. Blood samples were obtained from an indwelling brachial artery catheter and analyzed according to the following schedule:

1. Values obtained before skin incision, after induction of anesthesia, but before heparin had been given served as a baseline.

2. Values obtained 30 minutes after the start of CPB were used to directly compare the biocompatibility of heparin-coated surfaces and noncoated surfaces.

3. Values obtained 5 minutes after the aortic crossclamp was removed were used to measure the effect of heart and lung reperfusion injury.

4. Values obtained 5 minutes after the reversal of heparin with protamine reflected the effect of the heparinprotamine complex formation on platelet activation and thrombin generation.

The first $10 \mathrm{ml}$ of blood obtained from the arterial line was discarded; after plasma isolation and preparation, samples were stored at $-70^{\circ} \mathrm{C}$ until the time of assay. Enzyme-linked immunosorbent assays for $\beta$-TG (Asserachrom B-TG, Seine, France) and TAT III (Behring Diagnostics, Westwood, Mass.) were done according to instructions provided by the kit manufacturers. Surface expression of $\mathrm{P}_{- \text {selectin }}$ (CD 62) was measured by obtaining all blood samples in a diatube (sodium citrate, adenosine, theophylline). Flow cytometry was done by placing a $0.1 \mathrm{ml}$ aliquot of whole blood into $1.0 \mathrm{ml}$ of $0.1 \%$ paraformaldehyde at $4^{\circ} \mathrm{C}$ to stop platelet activation. Samples were incubated at $4^{\circ} \mathrm{C}$ for 1 hour. After mixing, samples were washed with phosphate-buffered saline solution and stained with use of a general platelet marker (CD 62-P, Becton-Dickinson, San Jose, Calif.). Dual-label flow cytometry was done in a Becton-Dickinson FACScan flow cytometer with Lysis II software. Results are presented as the percentage of platelets expressing CD 62 .

Scanning electron microscopy (SEM). In 12 patients ( 6 from each group), arterial filters were analyzed by SEM to determine in vivo platelet and leukocyte deposition and activation. The samples for SEM were taken from arterial filter meshworks as soon as possible after CPB. The filters 
Table I. Preoperative characteristics of patients undergoing CPB with heparin-coated or uncoated bypass circuit

\begin{tabular}{lccc}
\hline & \multicolumn{2}{c}{ Group } \\
\cline { 2 - 3 } Variable & $\begin{array}{c}\text { Heparin coated } \\
(n=24)\end{array}$ & $\begin{array}{c}\text { Uncoated } \\
(n=26)\end{array}$ & $p$ Value \\
\hline Age (yr) & $64 \pm 8$ & $64 \pm 11$ & 0.43 \\
Sex & & & \\
Male & 16 & 22 & 0.13 \\
Female & 8 & 4 & 0.66 \\
Hematocrit $(\%)$ & $40.25 \pm 5.13$ & $39.59 \pm 4.81$ & \\
Left ventricular & & & \\
$\quad$ dysfunction & $12(50 \%)$ & $15(65 \%)$ & \\
None & $6(25 \%)$ & $2(9 \%)$ & \\
Mild & $6(25 \%)$ & $4(15 \%)$ & 0.41 \\
Moderate & 0 & $1(4 \%)$ & NS \\
Severe & 21 & $22(84 \%)$ & NS \\
Preop. aspirin & 2 & $1(4 \%)$ & P. \\
Preop. heparin & &
\end{tabular}

Data are expressed as mean plus or minus standard deviation or as the number of patients. $N S$, Not significant.

first were rinsed three times with $0.1 \mathrm{~mol} / \mathrm{L}$ phosphate buffer with $3.0 \%$ sucrose solution ( $\mathrm{pH} 7.4$ ), then rinsed three times with $0.9 \%$ sodium chloride. The samples were subsequently fixed by immersion at $4^{\circ} \mathrm{C}$ for 12 hours with $2 \%$ glutaraldehyde in $0.1 \mathrm{~mol} / \mathrm{L}$ phosphate buffer with $3.0 \%$ sucrose (pH 7.4). To obtain specimens, the filter cases were cut open with a bandsaw. The filter material was carefully extracted, and four specimens ( 2 upstream and 2 downstream, each about $5 \mathrm{~mm}$ by 10 $\mathrm{mm}$ ) were cut from it. The specimens were marked with a cut so that the upstream and downstream orientations could be recognized. They were processed for SEM by a standard dehydration and gold-coating procedure that involved dehydration with a graded ethanol series and critical-point drying for 1 hour with liquid carbon dioxide. The specimens were mounted on aluminum studs with double-sided tape, a small amount of silver paint was applied around the edges, and the specimens were sputter-coated with gold to a final coating thickness of approximately $275 \AA$.

SEM was done with a JEOL JSM-T300 scanning electron microscope (JEOL, Peabody, Mass.) ás follows: 10 fields were selected randomly from each specimen. The magnification factor was $\times 500$. The field size on the cathode ray tube was $340 \mu \mathrm{m}$ wide by $260 \mu \mathrm{m}$ high, and the resultant area was $88,400 \mu \mathrm{m}^{2}$. Because two samples were obtained from the upstream and two from the downstream sides, a total of 40 fields was counted for each case. The individual field data were averaged to obtain values for each case. Data are reported as percent incidence divided by the fields observed ([number of observations/number of fields] $\times 100$ ). Cellular adhesion was measured for all formed blood elements. Leukocyte adhesion was further analyzed as to the degree of activation. Leukocytes were graded as having contact, spread, or
Table II. Procedures performed by tubing type used

\begin{tabular}{lrrr}
\hline & $\begin{array}{c}\text { Coated } \\
\text { tubing }\end{array}$ & $\begin{array}{c}\text { Noncoated } \\
\text { tubing }\end{array}$ & Total \\
\hline Coronary artery bypass graft & 13 & 17 & 30 \\
AVR & 2 & 3 & 5 \\
MVR/repair & 2 & 1 & 3 \\
AVR/coronary artery bypass graft & 2 & 0 & 2 \\
MVR/coronary artery bypass graft & 3 & 2 & 5 \\
AVR/MVR & 1 & 2 & 3 \\
AVR/MVR/coronary artery bypass & 1 & 0 & 1 \\
$\quad$ graft & & & \\
AVR/aortic conduit & -1 & -1 \\
$\quad$ Total & 24 & 26 & 50 \\
\hline
\end{tabular}

$A V R$, Aortic valve replacement; $M V R$, mitral valve replacement.

degranulation, depending on the degree of leukocyte activation seen according to the criteria of Marchant, Miller, and Anderson. ${ }^{14}$ The microscopists were unaware of the CPB circuit types used and the patient group assignment.

Statistical analysis. Data are presented as mean plus or minus standard deviation of the mean. Categorical data were analyzed by Fisher's exact test. The nonparametric Wilcoxon rank-sum test was used to determine whether the distributions of continuous variables differed between the two groups. For variables measured over time (hemostatic indices and ventilator weaning), repeated-measures analysis of variance with orthoganol polynomial trend was used. Significance was set at $p<0.05$.

To exclude any error induced by procedure done, the patients undergoing only coronary artery bypass grafting were analyzed separately.

Arterial filters were compared between the two subgroups. Total cell counts on the upstream and downstream sides were compared separately between groups. Within each group, the upstream and downstream sides were compared for differences in effectiveness of the arterial filter.

\section{Results}

Patient characteristics. All preoperative patient characteristics, including age, sex, heart function, preoperative aspirin use, and heparin use were similar for the two groups. Both treatment groups had similar preoperative risk scores (Table I). The types of procedures done were similar in each group (Table II).

Intraoperative patient care characteristics are shown in Table III. Both groups had similar CPB and crossclamp times and similar procedures done. Heparin use, protamine use, and $\epsilon$-aminocaproic acid use, as well as the mean number of grafts done, were likewise similar between groups. Intraoperative blood transfusion requirements did not differ between the two groups. 
Table III. Intraoperative patient characteristics compared by type of bypass used

\begin{tabular}{|c|c|c|c|}
\hline & \multicolumn{2}{|c|}{ Group } & \multirow[b]{2}{*}{$\begin{array}{c}p \\
\text { Valut }\end{array}$} \\
\hline & $\begin{array}{l}\text { Heparin coated } \\
\quad(n=24)\end{array}$ & $\begin{array}{l}\text { Uncoated } \\
(n=26)\end{array}$ & \\
\hline Bypass time (min) & $128.5 \pm 46.0$ & $121 \pm 42.5$ & 0.57 \\
\hline $\begin{array}{l}\text { Crossclamp time } \\
\text { (min) }\end{array}$ & $85.6 \pm 34.0$ & $78.3 \pm 31.1$ & 0.43 \\
\hline \multicolumn{4}{|l|}{ Procedures } \\
\hline Isolated CABG & $13(54 \%)$ & $17(65 \%)$ & \\
\hline $\mathrm{CABG}$ with valve & $6(25 \%)$ & $3(12 \%)$ & \\
\hline Isolated valve & $5(21 \%)$ & $6(23 \%)$ & \\
\hline Heparin (units) & $30,500 \pm 6,685.5$ & $30,308 \pm 6,583$ & 0.83 \\
\hline Protamine (mg) & $409.6 \pm 198.5$ & $356.0 \pm 157.0$ & 0.40 \\
\hline $\begin{array}{l}\text { E-Aminocaproic acid } \\
\text { (No. of pts. given) }\end{array}$ & 12 & 11 & 0.39 \\
\hline $\begin{array}{l}\text { Number of grafts } \\
\quad(\text { mean } \pm \text { SD })\end{array}$ & $2.17 \pm 1.01$ & $1.96 \pm 1.0$ & \\
\hline $\begin{array}{l}\text { Transfused blood } \\
\text { (units) }\end{array}$ & $2.8 \pm 2.1$ & $2.5 \pm 4.3$ & 0.15 \\
\hline $\begin{array}{l}\text { Higgins Severity } \\
\text { Score }^{13}\end{array}$ & $7.04 \pm 2.5$ & $6.19 \pm 2.8$ & 0.26 \\
\hline
\end{tabular}

$C A B G$, Coronary artery bypass grafting; $S D$, standard deviation.

Postoperative patient characteristics are shown in Table IV. Both groups had a similar number of units transfused per patient and a similar number of patients who required no transfusion. The two groups had similar amounts of chest tube drainage, and no difference was found in the time to extubation or the postoperative alveolar-arterial oxygen gradients or respiratory indices. Length of ICU stay was also similar between the two groups (Table IV). Two patients died postoperatively. In the noncoated group one patient died of respiratory insufficiency, adult respiratory distress syndrome, and subsequent lung infection. One patient in the heparin-coated group died of cardiac failure that had occurred intraoperatively. The morbidity rate was similar between the two groups. No patients required exploration for bleeding, and only one patient required reintubation in the heparin-coated group; the prevalence of myocardial infarction was greater in the heparin-coated group, but the difference was not statistically significant (Table V).

\section{Immunoassay results in all patients}

TAT III. Plasma TAT III levels increased significantly $(p<0.001)$ during bypass compared with baseline values. The levels continued to increase 5 minutes after the crossclamp was released and 5 minutes after protamine was administered (Fig. 1). No difference was found between the heparin-coated and the noncoated groups.
The variation between patients was large with respect to thrombin generation at times other than baseline.

$\beta$-TG levels. $\beta$-TG release increased significantly in both treatment groups at 30 minutes after $\mathrm{CPB}$ was started $(p<0.01)$. $\beta$-TG levels continued to increase 5 minutes after the crossclamp was released. No further increase was noted in the heparin-coated group after protamine was given (Fig. 2); however, $\beta$-TG levels did increase in the uncoated group after protamine was given. A large variation was seen between patients in each group 30 minutes after CPB was begun and at each subsequent interval.

$P$-selectin expression. CD 62 receptor expression increased significantly over baseline in both groups after 30 minutes of CPB $(p<0.01)$. No further increases occurred after crossclamp release or after protamine administration (Fig. 3), and these values did not differ significantly between groups. Again, variation was large between patients in each group.

Arterial filter analysis. The preoperative characteristics of the 12 patients in whom arterial filters were analyzed were similar with respect to age, sex, heart function, surgical risk, aspirin use, and previous electrocardiogram findings. They demonstrated no difference in bypass time, crossclamp time, heparin use, protamine use, $\epsilon$-aminocaproic acid use, procedures done, blood transfusion requirements, chest tube drainage, or ICU length of stay.

The total cell disposition was similar in the heparin-coated and uncoated groups, on both filter sides (Table VI). Similar amounts of cellular and proteinaceous deposition were seen on the coated and noncoated systems regardless of which side of the arterial filter was analyzed. Platelet deposition was less on the "up" side of the heparin-coated filters, but this difference was not statistically significant. As in the other analyses, variation between patients was large (Table VI).

Length of time of CPB was analyzed between the two bypass circuits and the side of filter analyzed. No correlation between length of time of CPB and degree of total cell adhesion or leukocyte activation was found.

There was no difference in the number of leukocytes adhering to the filter or in the degree of activation as measured by contact, spread, or degranulation. ${ }^{14}$ In general, the amount of leukocyte contact activation was low, but variation between patients was large.

Fig. 4 demonstrates, by photomicrographs, the degree of variability between the groups. Interpatient variability within groups was also large. 
Table IV. Postoperative patient characteristics

\begin{tabular}{|c|c|c|c|}
\hline & \multicolumn{2}{|c|}{ Group } & \multirow[b]{2}{*}{$p$ Value } \\
\hline & $\begin{array}{l}\text { Heparin coated } \\
\quad(n=24)\end{array}$ & $\begin{array}{l}\text { Uncoated } \\
(n=26)\end{array}$ & \\
\hline ICU blood transfusion (units) & $0.8 \pm 1.3$ & $1.2 \pm 1.8$ & 0.49 \\
\hline CT drainage & $644.0 \pm 354.4$ & $796.7 \pm 813.8$ & 0.985 \\
\hline \multicolumn{4}{|l|}{ Time to extubation } \\
\hline$\leq 1$ day & $22(91.7 \%)$ & $23(88.5 \%)$ & 0.999 \\
\hline$\geq 2$ days & $2(8.3 \%)$ & $3(11.5 \%)$ & \\
\hline \multicolumn{4}{|l|}{ Blood usage amount } \\
\hline \multicolumn{4}{|l|}{$\mathrm{OR}$} \\
\hline No blood & $5(21 \%)$ & $10(39 \%)$ & \\
\hline 1 unit & $4(17 \%)$ & $3(11 \%)$ & \\
\hline$>1$ unit & $15(62 \%)$ & $13(50 \%)$ & 0.455 \\
\hline \multicolumn{4}{|l|}{$\mathrm{ICU}$} \\
\hline No blood & $16(67 \%)$ & $15(57 \%)$ & \\
\hline 1 unit & $2(8 \%)$ & $2(8 \%)$ & \\
\hline$>1$ unit & $6(25 \%)$ & $9(35 \%)$ & 0.820 \\
\hline No. $(\%)$ of patients receiving no blood & $4(16.7 \%)$ & $7(26.9 \%)$ & 0.382 \\
\hline ICU LOS (days) & $2.04 \pm 1.0$ & $2.69 \pm 2.50$ & 0.175 \\
\hline \multicolumn{4}{|l|}{ Days in ICU } \\
\hline 1 day & $8(33 \%)$ & $10(39 \%)$ & \\
\hline 2 days & $10(42 \%)$ & $6(23 \%)$ & \\
\hline$>2$ days & $6(25 \%)$ & $10(39 \%)$ & 0.342 \\
\hline $\begin{array}{l}\text { Time to extubation (isolated CABG only) } \\
\geq 2 \text { days }(\%)\end{array}$ & $15.6 \pm 9.1$ & $20.8 \pm 9.5$ & 0.090 \\
\hline Alveolar-arterial $\mathrm{O}_{2}$ gradient at $4 \mathrm{hr}(\mathrm{mm} \mathrm{Hg})$ & $145.6 \pm 103.4$ & $153.0 \pm 87.9$ & 0.78 \\
\hline Respiratory index & $0.46 \pm 0.15$ & $0.46 \pm 0.16$ & 0.92 \\
\hline
\end{tabular}

$C T$, Chest tube; $O R$, operating room; $L O S$, length of stay; $C A B G$, coronary artery bypass grafting.

Immunoassay results: patients having coronary artery bypass grafting only. For patients undergoing coronary bypass grafting only $(n=30 ; n=13$ in the heparin-coated group and $n=17$ in the noncoated group), results were analyzed separately to eliminate potential confounding surgical factors related to valve replacement. This separate analysis also allowed for comparison with other studies in the literature, which typically analyzed only patients with bypass grafting. . $^{\text {-17 }}$

TAT III. Plasma TAT III levels increased significantly $(p<0.001)$ during bypass in the noncoated group. This increase was present but much less pronounced in the heparin-coated group. Thrombin generation occurred after crossclamp release, but little additional thrombin was generated after protamine administration. The coated and noncoated groups did not differ throughout the sampling period because of the large individual variations in response to $\mathrm{CPB}$ itself. These results were similar to those for patients undergoing valve operation or valve operation and bypass grafting (data not shown).
Table V. Postoperative morbidity and mortality after $C P B$ with heparin-coated or uncoated bypass circuit

\begin{tabular}{llll}
\hline & \multicolumn{2}{c}{ Group } & \\
\cline { 2 - 3 } & $\begin{array}{c}\text { Heparin coated } \\
(n=24)\end{array}$ & $\begin{array}{c}\text { Uncoated } \\
(n=26)\end{array}$ & $\begin{array}{c}p \\
\text { Value }\end{array}$ \\
\hline Morbidity & & & \\
Bleeding & $0(0 \%)$ & $2(8 \%)$ & 0.49 \\
Respiratory failure & $1(4.2 \%)$ & $4(15 \%)$ & 0.35 \\
Myocardial infarction & $3(13 \%)$ & $0(0 \%)$ & 0.10 \\
Cerebral vascular & $0(0 \%)$ & $1(4 \%)$ & 0.99 \\
$\quad$ accident & & & \\
Sepsis & $0(0 \%)$ & $0(0 \%)$ & - \\
IABP use & $2(8 \%)$ & $0(0 \%)$ & 0.26 \\
Mortality & $1(4 \%)$ & $1(4 \%)$ & 0.99 \\
\hline
\end{tabular}

$L A B P$, Intraaortic balloon pump.

$\beta$-TG levels. $\beta$-TG release increased significantly in both groups after CPB was begun $(p<0.01)$. $\beta$-TG levels continued to increase after crossclamp release. $\beta$-TG levels decreased in the heparincoated group after protamine was given but continued to increase in the noncoated group. Although 


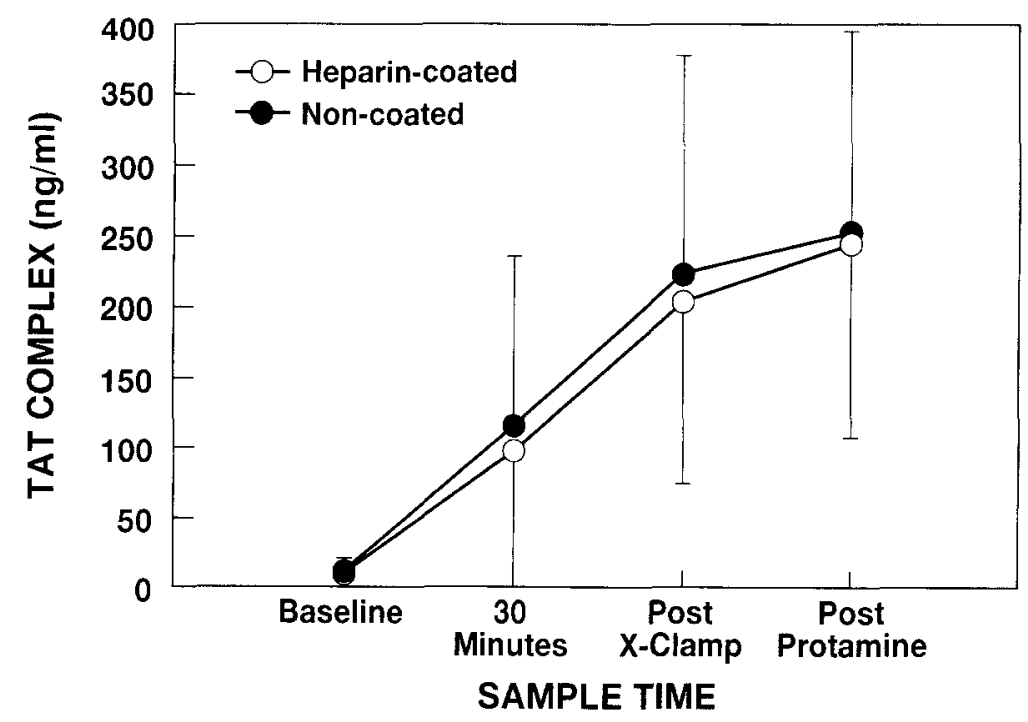

Fig. 1. Plasma TAT III levels are shown measured at four times during cardiac procedure in all 50 patients. Plasma levels increased in both groups in similar fashion after initiation of CPB, after crossclamp (X-clamp) was released, and slightly after protamine was given. There was no difference statistically between two groups.

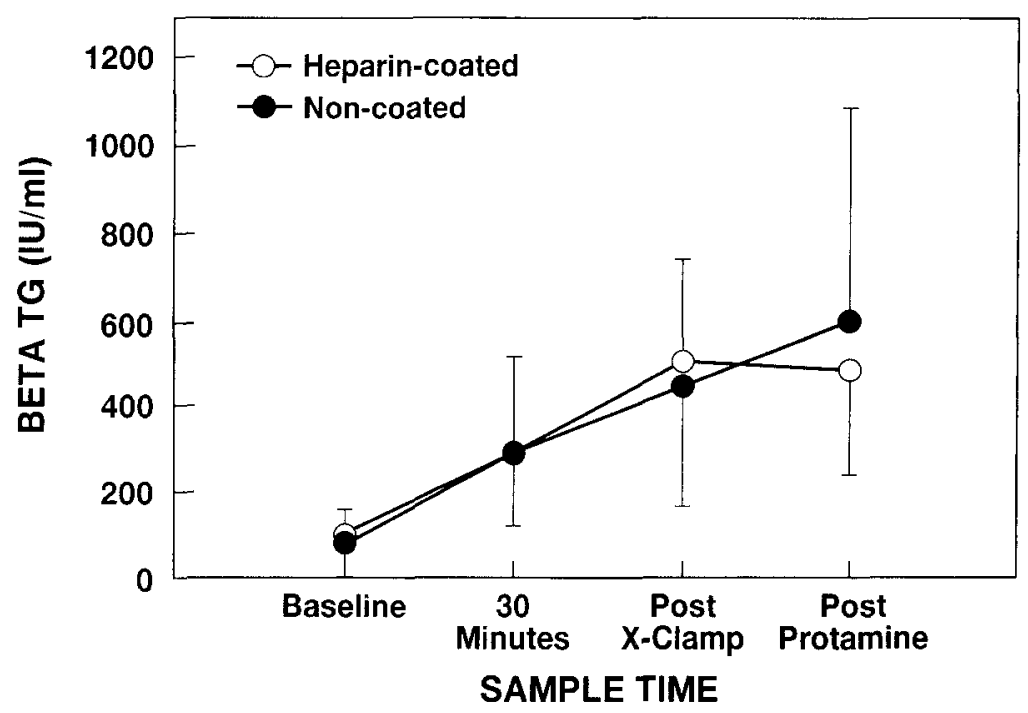

Fig. 2. Serum levels of $\beta$-TG release are shown from stimulated platelets at four times during cardiac procedure in all 50 patients. $\beta$-TG levels increased 30 minutes into bypass and after crossclamp $(X$-clamp) was released and in non-heparin-coated group continued to increase after protamine was given. No further increase was seen after protamine administration in heparin-coated group. There was no difference between two groups.

platelet activation appeared greater in the heparincoated group throughout bypass, there was no difference between the two groups. These results mirrored the results seen in the full study groups.

$P$-selectin expression. CD 62 receptor expression increased significantly over baseline values in both groups after 30 minutes of CPB $(p<0.01)$. Little additional increase in platelet activation was seen after crossclamp release or after protamine administration. CD 62 receptor expression did not differ significantly between the two groups largely because of individual variations in response dur- 


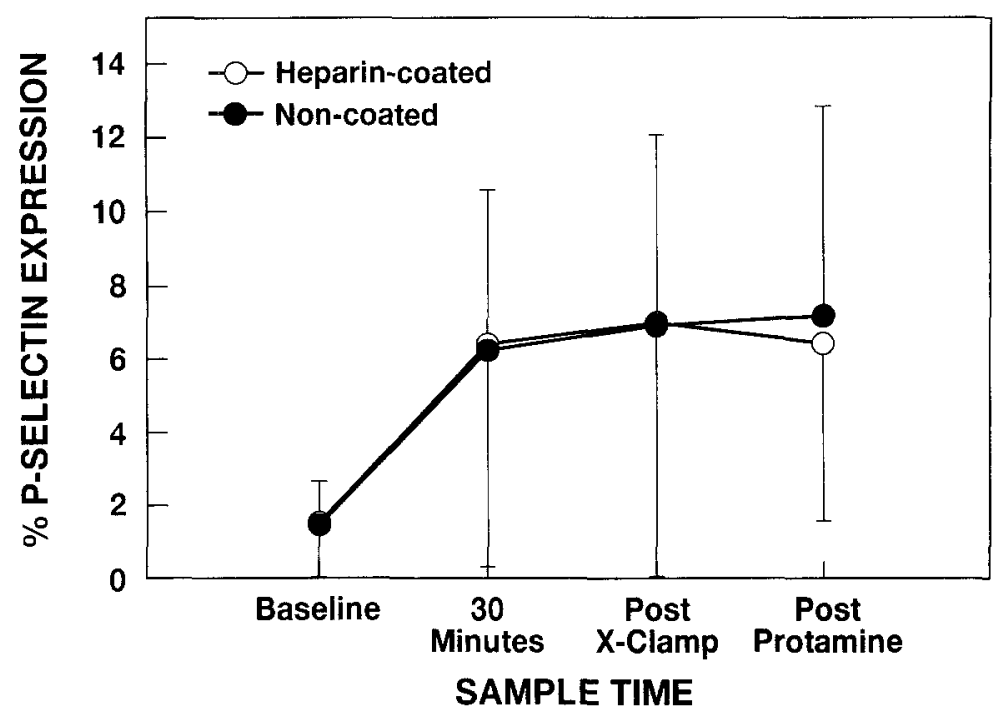

Fig. 3. Platelet marker CD 62 expression is shown at four times during cardiac surgical procedure. CD 62 receptor expression (P-selectin) was similar between heparin-coated and non-heparin-coated groups and increased markedly 30 minutes into bypass; however, no further increases were seen. There was no difference between two groups.

Table VI. Deposition of blood coagulation components on upstream and downstream sides of arterial filters in 12 patients

\begin{tabular}{lllll}
\hline Filter type and side & Leukocytes & Platelets & RBCs & Protein \\
\hline Uncoated circuit filters & & & & \\
$\quad(n=6)$ & & & & \\
$\quad$ Upstream side & $2.14 \pm 3.93$ & $4.29 \pm 6.07$ & $0.00 \pm 0.00$ & $4.29 \pm 9.32$ \\
$\quad$ Downstream side & $1.43 \pm 2.44$ & $2.14 \pm 2.67$ & $1.43 \pm 2.44$ & $3.57 \pm 5.56$ \\
$\quad$ Heparin-coated circuit filters & & & & \\
$\quad(n=6)$ & $5.00 \pm 10.00$ & $0.83 \pm 2.04$ & $0.83 \pm 2.04$ & $4.17 \pm 10.21$ \\
$\quad$ Upstream side & $1.67 \pm 2.58$ & $1.67 \pm 4.08$ & $0.00 \pm 0.00$ & $1.67 \pm 4.08$ \\
$\quad$ Downstream side &
\end{tabular}

Deposition is expressed as percent incidence: (number of component observations $\div$ number of SEM fields) $\times 100$. Values given as mean plus or minus standard deviation. There was no significant difference between the groups tested or between the different sides of the arterial filters tested. $R B C s$, Red blood cells.

ing bypass. These results are similar to those seen in the entire study group.

\section{Discussion}

We found that in patients undergoing reoperative coronary artery bypass or valve procedures the heparin-coated CPB circuit had no significant clinical or biochemical benefit over the standard uncoated circuit when a single crossclamp technique was used and pericardial blood was continuously returned to the bypass circuit. Both groups had similar preoperative and intraoperative characteristics, which makes it unlikely that any differences in duration of bypass, crossclamp times, patient characteristics, or procedures done affected the results.
Measurements of biocompatibility, including platelet activation, thrombin formation, and granulocyte activation, were done over the course of $\mathrm{CPB}$ and found not to differ between groups. Moreover, both groups had similar clinical outcomes with respect to duration of ventilation, alveolar-arterial oxygen gradient, blood loss, and transfusion requirements. However, given the limited number of patients in this study, the possibility of a type II error must be recognized.

Our study demonstrated several results unique to patients undergoing reoperative cardiac procedures. Thrombin generation occurred early in the bypass period and platelet stimulation occurred throughout the period of bypass, which has not been demon- 


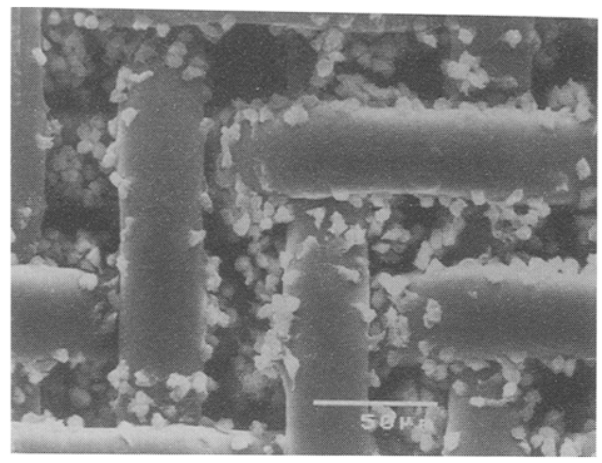

A

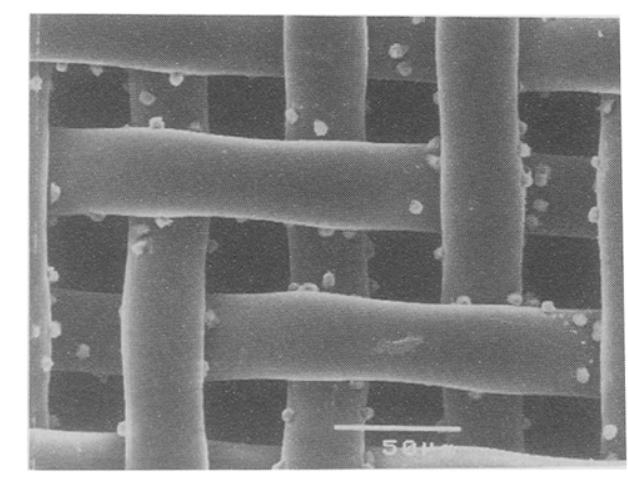

C

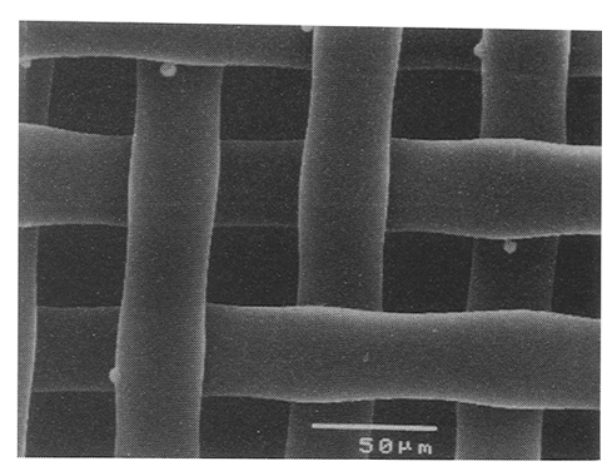

B

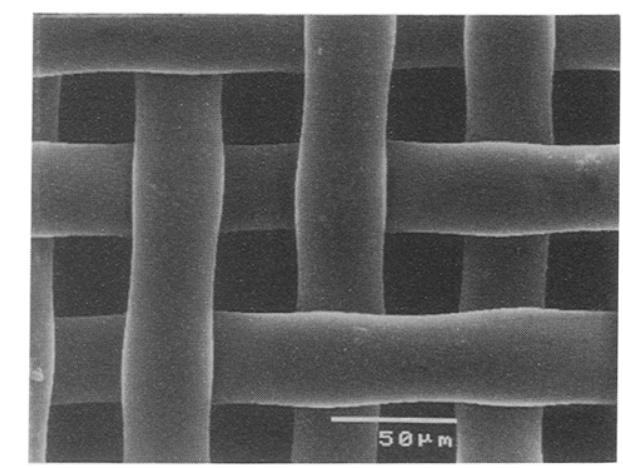

D

Fig. 4. SEM photomicrographs of arterial line filters demonstrating intragroup variability. A, Marked leukocyte adherence in noncoated group. B, Minimal leukocyte adherence in noncoated group. C, Marked leukocyte adherence to filter in heparin-coated group. D, Minimal leukocyte adherence in heparin-coated group.

strated before in patients undergoing primary or reoperative cardiac surgical procedures. Furthermore, our study revealed a tremendous individual patient variation in response to cardiac reoperation. This was consistently seen in both the biochemical markers of biocompatibility and on SEM evaluation of leukocyte activation. Wagner and associates ${ }^{11}$ looked at similar indices of thrombin and platelet activation in patients undergoing primary coronary artery bypass grafting with use of an uncoated cardiotomy reservoir and found that platelet activation occurred early during bypass but did not increase with aortic crossclamp release. Moreover, thrombin was not generated during bypass but was generated only after crossclamp release. It is likely that the early rise we observed in both platelet activation and thrombin generation represents both biomaterial-dependent and biomaterial-indepen- dent stimulation of platelets and the body's coagulation system.

Our finding of early thrombin generation during bypass and continued platelet activation after crossclamp release is likely related to biomaterial-independent factors such as our surgical technique and reoperative patient population. Our study design allowed for the free aspiration of shed pericardial blood throughout the $\mathrm{CPB}$ procedure, which may stimulate the body's defense system substantially. Tabuchi and associates ${ }^{17}$ have shown that the pericardial cavity stimulates blood components that come in contact with the cavity during CPB. Furthermore, blood aspirated from the pericardial sac had a heparin concentration that was only $20 \%$ of that in the completely heparinized systemic circulation. Moreover, thrombin levels and fibrin degenerative products were 40 times higher in blood aspi- 
rated from the pericardium than in blood in the bypass circuit. When reinfused blood collected from the pericardial cavity was placed back into the bypass circuit, thrombin production and fibrinolysis significantly increased in the systemic blood. These investigators concluded that tissue factor and tissuetype plasminogen activator accelerate activation of clotting and subsequently fibrinolysis in the pericardial cavity. ${ }^{17}$ This local activation contributes greatly to the systemic activation, affecting hemostasis during CPB. Tissue factor is a strong stimulus of the extrinsic clotting system, ${ }^{18}$ and tissue-type plasminogen activator activates the fibrinolytic system. ${ }^{19,20}$ De Haan and colleagues ${ }^{21}$ similarly demonstrated that retransfusion of activated pericardial blood during CPB clinically impairs hemostasis and exacerbates bleeding. Most likely, patients with abundant pericardial adhesions who are undergoing reoperation produce even greater tissue factor and tissue-type plasminogen activation than patients undergoing primary cardiotomy. The greater dissection involved with reoperation presumably produces a tremendous, yet variable biomaterial-independent stimulation of the body's defense mechanisms that overwhelms any biomaterial-dependent benefit of heparin-coated tubing of the extracorporeal circuit.

Although we were unable to demonstrate improved biocompatibility in our patients undergoing reoperation, this does not mean that heparin-coated tubing is not biocompatible. Other investigators have shown improved biocompatibility of heparincoated extracorporeal bypass circuits when aspirated pericardial blood is not returned to the systemic circulation. ${ }^{10,15,22}$ Typically, a red blood cell washing device is used to aspirate all pericardial blood, which is washed, centrifuged, and returned to the patient after operation. Fosse and associates ${ }^{16}$ found that complement activation and granulocyte stimulation were reduced in heparin-coated CPB circuits compared with findings in noncoated circuits. Pradham and colleagues ${ }^{12}$ have also shown that thrombin generation is significantly less (as measured by TAT III) in heparin-coated CPB circuits when cardiotomy suction is avoided. Neither Fosse and colleagues ${ }^{16}$ nor Pradham and colleagues ${ }^{12}$ found a reduction in chest tube drainage or blood transfusion requirement in patients treated with heparin-coated surfaces. There are, however, drawbacks to collecting shed pericardial blood and not retransfusing this blood at the time of operation. The use of a cell-saving device in lieu of cardiotomy suction is more expensive, and procedures with potential for extensive blood loss or that necessitate extensive deairing may not be suitable for heparincoated systems without cardiotomy aspiration capability. This may even increase the need for blood transfusions. Furthermore, it is unlikely that the cardiotomy reservoir itself is the cause of these changes, inasmuch as in our study the cardiotomy reservoir was heparin-coated. It is likely that our surgical population and technique allowed biomaterial-independent stimulation of the body's defense system to overwhelm any biomaterial-dependent mitigating properties of heparin-coated tubing.

The tremendous variability in individual patient responses to reoperative cardiac procedures was also demonstrated by analysis of arterial line filters. Moreover, our analysis of arterial line filters, which were heparin-coated in both groups, did not show a difference in total cell adhesion, platelet activation, or granulocyte activation between the two groups regardless of the side of the arterial filter evaluated. SEM is a reliable method for measuring leukocyte activation and fibrin deposition in vivo because it avoids in vitro contact activation, which is inherent in other methods. ${ }^{14}$ In general, variation was large within the two study groups, which may reflect the large variation in patient response to reoperative CPB. Borowiec and associates ${ }^{8}$ also found no difference between coated and uncoated CPB circuits when heparin-coated arterial filters were used in both study groups. Similarly, individual variability was high in this study. However, when uncoated filters were used, cell adhesion and activation differed significantly, which was believed to be caused by local filter activation of these blood components. For this reason, all arterial filters currently sold by Baxter Bentley are heparin-coated regardless of the rest of the bypass circuit. The large variation in platelet and leukocyte activation seen in our study supports the theory that individual patients respond differently and in varying degrees to the damaging effects of CPB and that other biomaterial-independent factors determine the degree of whole-body inflammatory response observed during CPB. Our results also suggest that this individual variation in inflammatory response is independent of the length of time of CPB.

To achieve clinical benefit from heparin-coated bypass circuits, several changes may be required in the way CPB is performed, including reducing systemic heparinization and avoiding aspiration of pericardial blood into the systemic circulation in an effort to reduce blood loss and complement activa- 
tion. Von Segesser and colleagues ${ }^{10,22}$ have shown that heparin-coated bypass circuits are safe with one third of the standard heparin dose $(1 \mathrm{mg} / \mathrm{kg})$ when all pericardial blood is collected with a cell-saving device and is not reinfused systemically. Patients in whom heparin-coated bypass circuits were used required less protamine and fewer blood transfusions; also a lower percentage of patients required transfusion. Pekna and associates, ${ }^{15}$ with use of a similar reduced dose of systemic heparinization and a fully coated bypass system, found significantly reduced complement activation. This finding may, however, have been partially a result of the use of less protamine to reverse the lower systemic dose of heparin in the heparin-coated group because heparin-protamine complexes activate complement and platelets. ${ }^{23}$ Nonetheless, use of less protamine may be an advantage. Some investigators have criticized reducing systemic heparinization with heparincoated bypass circuits because of the increased risk of thrombin generation and fibrin microemboli. ${ }^{24}$ Heparin does not prevent thrombin generation but rather potentiates the neutralizing effect of antithrombin III after thrombin is formed. Therefore the potential for clot formation may actually be increased. Cheung and colleagues ${ }^{25}$ have reported intracardiac clot formation when heparin-coated bypass circuits were used with reduced systemic heparinization $(1 \mathrm{mg} / \mathrm{kg})$. We also have reported an increased prevalence of intracardiac clot formation in patients maintained on extracorporeal life support with use of a heparin-coated circuit without systemic heparin. ${ }^{26}$ Clearly, further research is required to determine the safest strategy for use of heparin-coated bypass circuits in cardiac operations.

In conclusion, we found no benefit to the use of heparin-coated extracorporeal bypass circuits in patients undergoing reoperative cardiac procedures when similar doses of systemic heparinization were used in both groups with constant return of pericardial aspirated blood returned to the systemic circulation. However, these results must be interpreted cautiously because of the small sample size. Apparently, many biomaterial-independent stimulants to the whole-body inflammatory response occur at various times during bypass that may be more pronounced in patients undergoing reoperation. Fundamental changes in the way CPB is done are likely to be required to demonstrate the benefit of heparin-coated circuits in patients undergoing a variety of reoperative procedures. Not returning pericardial blood to the systemic circulation, limit- ing heart and lung reperfusion injury, and using specific priming solutions ${ }^{27,28}$ and perhaps antiinflammatory drugs may all be needed to elucidate the beneficial effects of biomaterial-dependent activation of the body's inflammatory response. Such major changes in the way CPB is done may limit the usefulness of heparin-coated circuits in patients undergoing reoperation.

We thank Sharon Grechny for help in preparing this manuscript and Shelly Sapp, PhD, for her statistical analysis, as well as Mary Sitz for data collection.

\section{REFERENCES}

1. Kirklin JK, Westaby S, Blackstone EH, et al. Complement and the damaging effects of cardiopulmonary bypass. J Thorac Cardiovase Surg 1983;86:845-57.

2. Butler J, Rocker GM, Westaby S. Inflammatory response to cardiopulmonary bypass. Ann Thorac Surg 1993;55:552-9.

3. Downing SW, Edmunds LH Jr. Released vasoactive substances during cardiopulmonary bypass. Ann Thorac Surg 1992;54:1236-43.

4. Utley J. Historical perspectives and basic pathophysiology of cardiopulmonary bypass. Semin Thorac Cardiovasc Surg 1990;2:292-9.

5. Rayston D. Blood activation. Semin Thorac Cardiovasc Surg 1990;2:341-57.

6. Thelin S, Bagge L, Hultman J, et al. Heparin-coated cardiopulmonary bypass circuits reduce blood cell trauma: experiments in the pig. Eur J Cardiothorac Surg 1991;5:486-91.

7. Videm V, Mollnes TE, Garred P, Svennevi JL. Biocompatibility of extracorporeal circulation: in vitro comparison of heparin-coated and uncoated oxygenators. J Thorac Cardiovasc Surg 1991;101:654-60.

8. Borowiec JW, Bylock A, van der Linden J, Thelin S. Heparincoating reduces blood cell adhesion to arterial filters during coronary bypass: a clinical study. Ann Thorac Surg 1993;55: 1540-5.

9. Larm O, Larsson R, Olsson P. A new non-thrombogenic surface prepared by selective covalent binding of heparin via a reducing terminal residue. Biomater Med Devices Artif Organs 1983;11:161-73.

10. von Segesser LK, Weiss BM, Pasic M, Garcia E, Turina MI. Risk and benefit of low systemic heparinization during open heart operations. Ann Thorac Surg 1994;58:391-8.

11. Wagner WR, Johnson PC, Thompson KA, Marrone GC. Heparin-coated cardiopulmonary bypass circuits: hemostatic alterations and postoperative blood loss. Ann Thorac Surg 1994;58:734-41.

12. Pradham MJ, Nkere UU, Arnold J, Wildevuur CRH, Taylor KM. Clinical experience with heparin-coated cardiopulmonary bypass circuits. Perfusion 1991;6:235-42.

13. Higgins TL, Estafanous FG, Loop FD, Beck GJ, Blum JM, Paranandi L. Stratification of morbidity and mortality outcome by preoperative risk factors in coronary artery bypass patients. JAMA 1992;267:2344-8.

14. Marchant RE, Miller KM, Anderson JM. In vivo biocompatibility studies: V-in vivo leukocyte interactions with Biomer. J Biomed Mater Res 1984;18:1169-90.

15. Pekna M, Hagman L, Haldén E, Nilsson UR, Nilsson B, 
Thelin S. Complement activation during cardiopulmonary bypass: effects of immobilized heparin. Ann Thorac Surg 1994;58:421-4.

16. Fosse E, Moen O, Johnson E, et al. Reduced complement and granulacyte activation with heparin-coated cardiopulmonary bypass. Ann Thorac Surg 1994;58:472-7.

17. Tabuchi $N$, de Hann J, Boonstra PW, van Oeveren W. Activation of fibrinolysis in the pericardial cavity during cardiopulmonary bypass. J Thorac Cardiovasc Surg 1993;106: 828-33.

18. Marlar RA, Kleiss AJ, Griffin JH. An alternative extrinsic pathway of human blood coagulation. Blood 1982;60:1353-9.

19. Van Hinsbergh VW, Kooistra T, Scheffer MA, von Boekel $\mathrm{JH}$, von Muijen GNP. Characterization and fibrinolytic properties of human omental tissue mesothelial cells: comparison with endothelial cells. Blood 1990;75:1490-7.

20. Collen D. Human tissue-type plasminogen activation. Circulation 1985;72:18-20.

21. de Hann J, Boonstra PW, Monnink SHJ, Ebels T, van Oeveren W. Retransfusion of suctioned blood during cardiopulmonary bypass impairs hemostasis. Ann Thorac Surg 1995;59:901-7.

22. von Segesser LK, Weiss BM, Garcia E, von Felton A, Turina
MI. Reduction and elimination of systemic heparinization during cardiopulmonary bypass. J Thorac Cardiovasc Surg 1992;103:790-9.

23. Kirklin JK, Chenoweth DE, Naftel DC, et al. Effects of protamine administration after cardiopulmonary bypass on complement, blood elements, and the hemodynamic state. Ann Thorac Surg 1986;41:193-9.

24. Edmunds LH Jr. Surface-bound heparin: panacea or peril? Ann Thorac Surg 1994;58:285-6.

25. Cheung AT, Levin SK, Weiss SJ, Acker MA, Stenach N. Intracardiac thrombus: a risk of incomplete anticoagulation for cardiac operations. Ann Thorac Surg 1994;58:541-2.

26. Muehrcke DD, McCarthy PM, Stewart RW, et al. Complications of extracorporeal life support systems using heparinbound surfaces: the risk of intracardiac clot formation. $J$ Thorac Cardiovasc Surg 1995;110:843-51.

27. Mellbye OJ, Froland SS, Lilleaasen P, Svennevig J-L, Mollnes TE. Complement activation during cardiopulmonary bypass: comparison between the use of large volumes of plasma and dextran 70. Eur Surg Res 1988;20:101-9.

28. Bosner RS, Dave JR, Davies ET, et al. Reduction of complement activation during bypass by protamine manipulation. Ann Thorac Surg 1990;69:1-4. 